\title{
PERAN NILAI HEDONIK MEMEDIASI PENGARUH ATMOSFER GERAI TEHADAP PEMBELIAN IMPULSIF (Studi Pada Konsumen Level 21 Mall Denpasar)
}

\author{
I Putu Rama Wijaya ${ }^{1}$ \\ I Gde Ketut Warmika ${ }^{2}$ \\ ${ }^{1,2}$ Fakultas Ekonomi dan Bisnis Universitas Udayana, Bali, Indonesia \\ email: ramawijaya905@yahoo.com
}

\begin{abstract}
ABSTRAK
Tujuan penelitian ini untuk mengetahui pengaruh atmosfer gerai terhadap pembelian impulsif melalui nilai hedonik sebagai pemediasi. Sampel penelitian ditetapkan sebanyak 75 responden dengan teknik pengambilan sampe yaitu purposive sampling. Teknik analisis yang digunakan adalah path analysis dengan uji asumsi klasik dan uji sobel Penelitian ini diharapkan dapat memberikan kontribusi empiris tentang pengaruh antara variable atmosfer gerai, nilai hedonik, dan pembelian impulsif bagi perkembangan ilmu pengetahuan dan menjadi bahan pertimbangan manajemen pemasaran perusahaan. Hasil penelitian menunjukkan bahwa atmosfer gerai berpengaruh positif dan signifikan terhadap nilai hedonik. Atmosfer gerai berpengaruh positif dan signifikan terhadap pembelian impulsif. Nilai hedonik berpengaruh positif dan signifikan terhadap pembelian impulsif. Nilai hedonik secara signifikan memediasi pengaruh atmosfer gerai terhadap pembelian impulsif.
\end{abstract}

Kata kunci: atmosfer gerai, nilai hedonik, pembelian impulsif

\begin{abstract}
Thi study aims to determine the effect of the outlet atmosphere on impulsive purchases through hedonic values as a mediator. The research sample was set as many as 75 respondents using a sampling technique that is purposive sampling. The analysis technique used is path analysis with the classic assumption test and the sobel test This research is expected to be able to make empirical contributions about the influence between outlet atmosphere variables, hedonic values, and impulsive purchases for the development of science and become a consideration for company marketing management. The result showed that the outlet atmosphere had a positive and significant effect on hedonic values. Outlet atmosphere has a positive and significant effect on impulsive purchases. The hedonic value has a positive and significant effect on impulsive purchases. The hedonic value significantly mediates the effect of the outlet atmosphere on impulsive purchases.

Keywords: outlet atmosphere, hedonic value, impulsive buying
\end{abstract}




\section{PENDAHULUAN}

Pada saat ini industri ritel di Indonesia sedang mengalami pertumbuhan yang sangat cepat. Sopiah dan Syihabuddin (2008:121) mengungkapkan globalisasi juga merupakan faktor utama terciptanya permintaan atau meningkatnya permintaan barang dan jasa ritel. Pertumbuhan perekonomian dan perkembangan zaman yang semakin modern berdampak pada pergeseran budaya belanja masyarakat. Fenomena ini dapat dibuktikan dengan adanya perubahan gaya hidup masyarakat yang dahulu berbelanja di pasar tradisonal, namun saat ini masyarakat lebih suka berbelanja di pasar modern seperti mall dan department store. Indonesia merupakan negara yang terdiri dari banyak pulau, dan juga terdiri dari banyak ras, suku, dan budaya. Salah satu tempat di Indonesia yang paling banyak dikunjugi oleh wisatawan lokal maupun manca negara adalah Bali. Bali merupakan pulau yang terkenal akan budayanya, dan keindahaan alamnya. Masyarakan yang kental akan budaya dan juga selalu menjaga tradisi secara turun temurun, alam yang masih asri dan terjaga yang membuat Bali memiliki daya tarik tersendiri bagi wisatawan. Masyarakat Bali yang ramah dan objek wisata yang banyak merupakan salah satu yang membuat wisatawan senang saat berada di Bali.

Banyaknya wisatawan lokal maupun manca negara yang datang ke Bali yang menyebabkan banyak peluang bisnis yang ada di Bali khususnya di kota Denpasar. Denpasar merupakan merupakan ibu kota provinsi Bali. Banyaknya perkantoran dan juga pusat pemerintahan di kota Denpasar menyebabkan Denpasar menjadi salah satu daerah terpadat penduduk di Bali. Selain perkantoran di kota Denpasar juga terdapat banyak kampus maupun tempat pelatihan pekerjaan. Padatnya kota Denpasar menyebabkan banyaknya ada peluang bisnis yang ada di kota Denpasar. Salah satu peluang bisnis yang ada di kota Denpasar adalah bisnis ritel, hal tersebut bisa dilihat dari banyaknya mall dan departement store yang ada di Denpasar. Ritel merupakan suatu upaya yang dilakukan perusahaan manufaktur dalam mendistribusikan barang - barangnya dalam jumlah yang besar untuk dikonsumsi oleh konsumen dalam memenuhi kebutuhannya (Utami, 2010:5). Tiara Dewata, Matahari Duta Mall Plaza, dan juga Ramayana merupakan mall yang sudah berdiri sejak lama di Denpasar, sedangkan Level 21 Mall, Plaza Renon, dan juga Trans Studio Mall merupakan mall pendatang baru di Denpasar.

Berdasarkan hasil survei yang sudah dilakukan, 21 dari 30 orang atau 70 persen memilih Level 21 Mall sebagai mall yang paling sering dikunjungi di kota Denpasar. Alasan orang sering mengunjungi Level 21 Mall Denpasar karena tempatnya yang strategis yang mudah di jangkau dan berada di tengah kota, tatanan gerai yang rapi sehingga orang lebih gampang menemukan gerai yang dicari, kebersihan dan kerapian di dalam gerai yang selalu dijaga sehingga orang merasa senang dan nyaman saat melakukan perbelanjaan atau hanya sekedar jalan - jalan. Menurut Yistiani dkk. (2012) bila pelanggan merasa senang dan merasa nyaman saat berbelanja di suatu gerai maka kemungkinan untuk melakukan pembelian yang bersifat impulsif juga akan semakin meningkat, yang bererti nilai hedonik atau kesenangan dapat mempengaruhi pembelian impulsif. Menurut (Wahyudi, 2017) Konsumen sebagai pengambil keputusan pembelian seringkali tanpa ada rencana melakukan pembelian terhadap suatu produk secara spontan begitu mereka berbelanja di mall, pasar swalayan, supermarket ataupun toko. 
Level 21 Mall Denpasar berlokasi di jalan Teuku Umar No. 1 Dauh Puri Klod Denpasar - Bali. Lokasi mall yang strategis berada di tengah kota Denpasar dan juga parkiran yang luas merupakan salah satu kelebihan dari Leval 21 Mall. Berdasarkan hasil survei Level 21 Mall Denpasar memiliki 90 gerai yang ada di dalam mall. Level 21 Mall memiliki fasilitas yang tergolong lengkap mulai dari parkir yang luas, lift, toilet, smoking area, rest area, food area, gym area dan juga produk pakaian yang banyak dicari contohnya the executive dan guess ada. Bioskop yang ada di Level 21 Mall merupakan bioskop yang paling sering di pilih untuk menonton film, walaupun harga tiketnya yang terbilang mahal, namun fasilitas yang ada di bioskop seperti kursinya yang lebih bagus, toilet yang bersih, film yang ada di bioskop lebih beragam, tiket bisoskop dapat di pesan secara online sehingga lebih praktis, dan pelayanan yang ramah merupakan kelebihan dari bioskop di Level 21 Mall Denpasar. Fasilitas yang lengkap merupakan salah satu alasan banyak konsumen memilih Level 21 Mall Denpasar, sehingga konsumen lebih sering mengunjungi Level 21 Mall dibandingkan mall yang lain yang ada di kota Denpasar. Semakin sering konsumen mengunjungi Lvel 21 Mall dapat menyebabkan atau memicu terjadinya pembelian terencana maupun pembelian tidak terencana. Pembelian terencana adalah pembelian yang dilakukan secara terenca atau tersusun sebelum melakukan perbelanjaan atau konsumen sudah mengetahui apa saja yang akan dibeli, dan konsumen cenderung membeli produk yang sudah direncanakan sebelumnya sehingga enggan memembeli produk lain, konsumen yang seperti ini biasanya lebih mementingkan kebutuhan primer dibandingkan kebutuhan skunder. Pembelian tidak terencana adalah pembelian yang terjadi secara spontan, dimana konsumen secara spontan atau tidak berfikir pada saat melihan suatu produk tertentu kemudian konsumen melakukan pembelian pada produk tersebut, biasa pembelian ini terjadi pada saat konsumen terburu - buru saat berbelanja, dan pada saat konsumen melihat susuatu yang menarik dan membelinya secara spontan, konsumen yang melakukan pembelian ini biasanya tergolong konsumen yang membeli produk skunder atau kebutuhan primernya sudah terpenuhi sehingga saat ia melihat suatu produk yang menarik maka ia akan terangsang atau terdorong untuk membeli produk tersebut.

Pembelian impulsif merupaka prilaku belanja yang terjadi secara tidak sengaja dimana keputusan pembelian dibuat secara cepat dan tanpa berfikir secara bijak atas pertimbangan yang ada. Pembelian impulsif adalah perilaku belanja yang terjadi secara tidak terencana dalam keadaan pembuatan keputusan secara cepat tanpa memikirkan akibat (Muruganantham \& Bhakat, 2013). Berfikir tanpa akibat yang dimagsud adalah dimana konsumen tidak memikirkan akibat dari membeli produk tertentu saat ia melakuka sutu pembelian secara spontan. Harmancioglu dkk. (2009) menyatakan, pembelian tidak terencana merupakan seluruh pembelian yang dibuat tanpa rencana terlebih dahulu. Menurut (Choudhary, 2014) seringkali dorongan batin kita atau godaan untuk membeli sesuatu tertentu meningkat sedemikian rupa sehingga tanpa tingkat perencanaan kita melompat ke pembelian. Fenomena pembelian impulsif atau impulse buying terjadi sejak lama dikenal dan menjadi bagian dari dunia pemasaran. Konsumen yang melakukan pembelian impusif cenderung tidak berfikir untuk membeli produk atau merek tertentu. Menurut Khorrami dkk. (2015) Bentuk pembelian ini tidak disengaja 
karena individu belum mencari produk tertentu dan tidak memiliki niat sedikit pun untuk membeli. Adanya prosduk yang menarik, potongan harga terhadap suatu produk, dan juga produk yang sedang trend merupakan salah satu dorongan atau penyebab konsumen melakukan pembelian secara spontan saat melihat produk tersebut. Berdasarkan penelitian sebelumnya dapat disimpulkan bahwa pembelian impulsive yaitu pembelian yang tidak direncanakan atau pembelian yang dilakukan di luar daftar belanja yang sudah ada, terjadi di dalam toko dan dialami konsumen secara spontan dan tanpa memikirkan resiko. Menurut Bayley \& Nancarrow (1998), Pancaningrum (2017), Yistiani dkk. (2012), Purwa \& Yasa (2014), Supriyono \& Iskandar (2016) menyebutkan indikator dari variabel pembelian impulsif adalah pembelian dengan spontan, pembelian tanpa berfikir akibat, pembelian terburu-buru, pembelian dipengaruhi keadaam emosional.

Sebagian besar keputusan dalam pembelian terjadi di dalam gerai atau toko. Menurut Vinayagamoorthy \& Kannan (2015) tahap pra-keputusan pembelian mengasosiasikan pembeli ini dengan pembelian yang tidak direncanakan atau impuls karena toko penuh dengan berbagai produk dan pembeli dapat dengan mudah tertarik untuk membeli produk yang menarik baginya. Keinginan konsumen untuk berbelanja dapat diwujudkan melalui atmosfer gerai yang disajikan oleh toko tersebut. Menurut Berčík dkk. (2016) untuk menarik perhatian konsumen dan kemudian memilih produk adalah dengan cara mengatur posisi produk di rak, musik, warna, pencahayaan dan aroma yang secara langsung dapat mempengaruhi emosi konsumen. Menurut Levy \& Weitz (2012:467) pemilihan desain toko yang baik akan menarik konsumen untuk datang ke toko, meningkatkan waktu yang dihabiskan dalam toko, juga dapat meningkatkan jumlah produk yang akan dibeli. Store atmosphere merupakan salah satu elemen penting dari retailing mix yang mampu mempengaruhi proses keputusan pembelian konsumen, karena dalam proses keputusan pembeliannya konsumen tidak hanya memberi respon terhadap barang dan jasa yang ditawarkan oleh retail (Angga dkk., 2018). Berdasarkan hasil penelitian sebelumnya dapat disimpulkan bahwa atmosfer gerai merupakan lingkungan dalam dan luar toko yang beberapa diantaranya adalah pencahayaan, warna, bau dan musik yang dibuat sedemikian rupa oleh para pengusaha untuk mempengaruhi konsumen. Menurut Ma' ruf (2015), Hussain \& Ali (2015), Supriyono \& Iskandar (2016) dan Yistiani dkk. (2012) menyebutkan indikator dari atmosfer gerai adalah tata cahaya, display, warna, sistem pengaturan udara, aroma, dan musik.

Menurut Madhuhansi (2017) karena adanya ketertarikan terhadap gerai (dari segi musik dan juga cahaya yang ada di dalam gerai) dapan meniarik minat konsumen ke dalam gerai tersebut sehingga terjadi pembelian impulsif. Suasana toko yang mendukung maka akan meningkatkan kenikmatan dan kesenangan (hedonisme) konsumen saat berbelanja. Semakin rapi, nyaman, dan juga bersih suasana gerai maka dapat meningkatkan nilai hedonik pada konsumen. Menurut Yudhistira dkk. (2018) Atmosfer toko yang dirancang dengan baik oleh peritel selain untuk mengundang konsumen untuk datang, juga dapat mempengaruhi perilaku pembelian konsumen dengan menciptakan suasana yang nyaman akan menciptakan perasaan senang bagi konsumen, perasaan senang itu akan mendorong perilaku belanja konsumen seperti hedonic shopping value atau nilai belanja 
hedonis. Hedonic shoping value mengacu pada tingkat persepsi di mana belanja dianggap secara emosional bermanfaat melalui berbagai perasaan positif dan berharga (Irani \& Hanzaee, 2011). Nilai hedonik merupakan suatu emosi yang dapat memicu konsumen untuk melakukan kegiatan berbealanja pada suatu gerai. Saat konsumen merasa senang atau nyaman saat berada di dalam gerai dapat meningkatkan nilai hedonik pada konsumen.

Nilai hedonik merupakan bagian dari instrument pengalaman belanja, yang mencerminkan instrumen yang menyajikan secara langsung manfaat dari suatu pengalaman dalam melakukan pmbelanjaan, seperti : kesenangan dan hal - hal baru (Semuel, 2006). Menurut Engel, Blackwell, Roger D. dan Miniard (1994:285) hedonis memiliki maanfaat lebih subjektif dan indivual. Menurut Solomon (2006:312) nilai hedonis merupakan hal menyenangkan dan tidak berwujud. Menurut Gultekin \& Hacettepe (2012) belanja hedonik terdiri dari emosi seperti ceria, kecemburuan, ketakutan, gairah dan kesenangan. Nilai belanja hedonis menciptakan kepuasan dan kebahagiaan yang terjadi pada konsumen ketika berbelanja dengan kata lain kepuasan dan kesenangan yang didapat konsumen setelah berbelanja memiliki kecenderungan untuk melakukan kembali pembelian untuk memperoleh kembali kesenangan dan kepuasan tersebut (Yudhistira dkk., 2018). Menurut Supriyono \& Iskandar (2016) hedonis mencerminkan nilai-nilai pengalaman belanja yang mencakup fantasi, gairah, sensorik rangsangan, kenikmatan, kesenangan, rasa ingin tahu, dan pelarian. Oleh karena itu, konsumen tersebut akan mencari lingkungan berbelanja yang memberikan tingkat kenyamanan yang tinggi agar kegiatan belanja yang dilakukan menjadi lebih menyenangkan. Berdasarkan hasil penelitian sebelumnya dapat disimpulkan bahwa nilai hedonik adalah prilaku konsumen yang bertujuan untuk memenuhi kebutuhan pribadi dan kesenangan dengan mengabaikan perencanaan pembelilan yang telah ditentukan sebelumnya atau nilai hedonik adalah suatu nilai kepuasan yang didapatkan oleh konsumen saat melakukan perbelanjaan. Menurut Scarpi (2006), Supriyono \& Iskandar (2016), Yistiani dkk. (2012) menyebutkan indikator dari variabel nilai hedonik adalah kenikmatan, kesenangan, keingintahuan, interaksi sosial.

Berdasarkan hasil penelitian sebelumnya terdapat perbedaan hasil penelitian yang di indikasikan terjadinya gap analysis dan juga berdasarkan hasil survei yang menyatakan responden lebih sering mengunjungi Level 21 Mall Denpasar dibandingkan dengan mall lainnya yang ada di Denpasar, maka akan dilakuka penelitian dengan topik "Peran Nilai Hedonik Memediasi Pengaruh Atmosfer Gerai Terhadap Pembelia Impulsif (Studi Pada Konsumen Level 21 Mall Denpasar)".

Ballantine dkk. (2010) menemukan bahwa elemen-elemen atmosfer gerai dapat menjadikan pengalaman berbelanja konsumen menjadi menyenangkan sehingga membangkitkan emosi konsumen dan menciptakan nilai hedonik. Penelitian dari Yistiani dkk. (2012) juga menemukan bahwa atmosfer gerai memiliki pengaruh yang signifikan terhadap nilaii hedonik yang berarti semakin baik atmosfer yang diciptakan dalam gerai maka dapat meningkatkan timbulnya nilai hedonik pelanggan pada gerai yang bersangkutan. Serta penelitian dari Prasetyo dkk. (2016) yang menyatakan bahwa 
store atmosphere berpengaruh signifikan terhadap hedonic shopping value. Berdasarkan penelitian sebelumnya, dapat dibangun hipotesis sebagai berikut.

$\mathrm{H}_{1}$ : Atmosfer gerai berpengaruh positif dan signifikan terhadap nilai hedonik

Menurut Supriyono \& Iskandar (2016) atmosfer toko berpengaruh negatif dan signifikan terhadap pembeliaan impulsive, hal ini menunjukkan semakin meningkatnya atmosfer toko akan menurun pembeliaan impulsive secara signifikan. Berdasarkan penelitian Roy (2018) atmosfer gerai seperti tampilan jendela, di signage promosi toko dan tata letak toko memainkan peran penting dalam meningkatkan perilaku pembelian impuls pelanggan. Menurut Vinayagamoorthy \& Kannan (2015) tahap pra-keputusan pembelian mengasosiasikan pembeli ini dengan pembelian yang tidak direncanakan atau impuls karena toko penuh dengan berbagai produk dan pembeli dapat dengan mudah tertarik untuk membeli produk yang menarik baginya. Atmosfer toko berpengaruh signifikan terhadap pembelian tidak terencana (Yudhistira dkk., 2018). Menurut Pemayun \& Ekawati (2016), Akram dkk., (2016), Dewi \& Giantari (2015) atmosfer gerai berpengaruh positif dan signifikan terhadap pembelian impulsif. Berdasarkan penelitian sebelumnya dapat dibangun hipotesis sebagai berikut.

$\mathrm{H}_{2}$ : Atmosfer gerai berpengaruh positif dan signifikan terhadap pembelian impulsif

Menurut Zayusman \& Septrizola (2019) variabel hedonic shopping value tidak berpengaruh signifikan terhadap impulse buying. Berdasarkan penelitian Prasetyo dkk., (2016) dan Yudhistira dkk., (2018) menyatakan bahwa variabel hedonic shopping value berpengaruh signifikan terhadap impulse buying, begitu juga dengan penelitan Ratnasari dkk. (2015) dan Kartika dkk. (2017) yang menyatakan bahwa variabel hedonic shopping value berpengaruh signifikan terhadap variabel impulse buying, serta penelitian dari Yistiani dkk., (2012) menemukan bahwa nilai hedonik memiliki pengaruh yang positif dan signifikan terhadap pembelian impulsif, yang berarti semakin besar nilai hedonik yang dirasakan pelanggan maka akan dapat meningkatkan kemungkinan terjadinya pembelian impulsif pada gerai yang bersangkutan. Berdasarkan penelitian sebelumnya dapat dibangun hipotesis sebagai berikut.

$\mathrm{H}_{3}$ : Nilai hedonik berpengaruh positif dan signifikan terhadap pembelian impulsif Berdasarkan penelitian dari Yistiani dkk. (2012) menunjukan nilai hedonik sebagai variabel mediasi antara atmosfer gerai dan pembelian impulsif tampak tidak memberikan pengaruh yang terlalu signifikan. Kemudian, Setiawati \& Sukawati (2017) menunjukan atmosfer gerai memiliki pengaruh positif dan signifikan secara tidak langsung terhadap pembelian impulsif dengan nilai hedonik sebagai variabel intervening. Serta, penelitian dari Prasetyo dkk. (2016) menunjukan bahwa hedonic shopping value terbukti sebagai variabel intervening dalam hubungan antara store atmosphere dengan impulse buying. Berdasarkan penelelitian sebelumnya dapat dibangun hipotesis sebagai berikut.

$\mathrm{H}_{4}$ : Nilai hedonik berperan dalam memediasi pengaruh atmosfer gerai terhadap pembelian impulsif 


\section{METODE PENELITIAN}

Lokasi penelitian ini dilakukan di Level 21 Mall yang beralamat di jalan Teuku Umar No. 1 Dauh Puri Klod Denpasar - Bali. Alasan dilakukan penelitian di Level 21 Mall karena Level 21 Mall adalah berdasarkan hasil survei 21 dari 30 orang memilih Level 21 Mall sebagai mall yang paling sering di kunjungi.Alasan orang sering mengunjungi Level 21 Mall Denpasar karena tempatnya yang strategis yang mudah di jangkau dan berada di tengah kota, tatanan gerai yang rapi sehingga orang lebih gampang menemukan gerai yang dicari, kebersihan dan kerapian di dalam gerai yang selalu dijaga sehingga orang merasa senang dan nyaman saat melakukan perbelanjaan atau hanya sekedar jalan - jalan. Gerai yang ada di Level 21 Mall yang tergolong lengkap, mulai dari gerai makanan, gadget, pakaian, gym, dan juga bioskop merupakan salah satu alasan konsumen memilih mengunjungi Level 21 Mall Denpasar. Semakin sering dan semakin banyak orang mengunjungi Level 21 Mall Denpasar, maka semakin tinggi peluang terjadinya pembelian impulsif. Populasi pada penelitian ini adalah konsumen Level 21 Mall Denpasar. Teknik non - probability samplingyang dipilih adalah purpose sampling yaitu teknik penentuan sampel dengan pertimbangan kriteria tertentu. Adapun kriteria responden yang diambil sebagai sampel adalah yang sudah pernah berbelanja di Level 21 Mall Denpasar, yang berdomisili di kota Denpasar, pernah melakukan pembelian impulsif, dan juga pendidikan terakhirnya adalah SMA/SMK. Responden dari penelitian ini adalah sebanyak 75 responden. Analisis jalur digunakan untuk menentukan pola hubungan antara tiga atau lebih dan tidak dapat digunakan untuk mengkonfirmasi atau menolak hipotesis. Uji asumsi klasik digunakan agar diketahui apakah model bersitribusi norlmal, mencari apakah ada korelasi antara variabel dan juga menguji model regresi apakah terjadi ketidaksamaan varian dari residual satu pengamatan yang lain.

\section{HASIL DAN PEMBAHASAN}

Uji validitas dilakukan dengan mengkorelasikan antara skor faktor dengan skor total dan bila korelasi tiap faktor tersebut bernilai positif $(r>$ 0,3), maka instrumen penelitian tersebut dapat dikatakan valid. Instrumen yang valid adalah instrumen yang dapat digunakan untuk mengukur apa yang seharusnya diukur. Tinggi rendahnya validitas menunjuk kan sejauh mana data yang terkumpul tidak menyimpang dari gambaran tentang variabel yang dimaksud. Hasil uji validitas penelitian ini ditunjukkan dalam Tabel 1.

Tabel 1. menunjukkan bahwa seluruh instrumen variabel penelitian berupa atmosfer gerai, nilai hedonik dan pembelian impulsif telah memenuhi syarat uji validitas yang dimana nilai skor total Pearson Correlation masing-masing instrumen berada diatas 0,30 maka instrumen valid dan layak digunakan sebagai instrumen penelitian.

Uji pada instrumen penelitian guna memperoleh hasil instrumen yang dapat dipercaya dan diandalkan digunakan uji reliabilitas. Pengujian ini, nilai suatu reliabilitas ditunjukkan melalui skor Cronbach's Alpha yang dimana jika nilai skor tersebut berada diatas 0,60 maka instrumen tersebut dapat dikatakan reliabel. Hasil penelitian uji reliabilitas dapat dilihat pada Tabel 2. 
Tabel 1.

Hasil Uji Validitas

\begin{tabular}{ccccc}
\hline No & Variabel & Instrumen & $\begin{array}{c}\text { Pearson } \\
\text { Correlation }\end{array}$ & Keterangan \\
\hline 1 & Atmosfer Gerai (X) & X1.1 & 0,814 & Valid \\
& & X1.2 & 0,798 & Valid \\
& X1.3 & 0,829 & Valid \\
& X1.4 & 0,917 & Valid \\
& X1.5 & 0,857 & Valid \\
& & X1.6 & 0,902 & Valid \\
2 & \multirow{3}{*}{ Nilai Hedonik (Y1) } & Y1.1 & 0,858 & Valid \\
& & Y1.2 & 0,894 & Valid \\
& & Y1.3 & 0,829 & Valid \\
& & Y1.4 & 0,827 & Valid \\
& & Y1.5 & 0,902 & Valid \\
3 & Pembelian Impulsif (Y2) & Y2.1 & 0,891 & Valid \\
& & Y2.2 & 0,894 & Valid \\
& & Y2.3 & 0,883 & Valid \\
& & Y2.4 & 0,928 & Valid \\
\hline
\end{tabular}

Sumber: Data diolah, 2019

Tabel 2.

Hasil Uji Reliabilitas Instrumen Penelitian

\begin{tabular}{llcc}
\hline No. & \multicolumn{1}{c}{ Variabel } & Cronbach's Alpha & Keterangan \\
\hline 1. & Atmosfer Gerai (X) & 0,925 & Reliabel \\
2. & Nilai Hedonik (Y1) & 0,913 & Reliabel \\
3. & Pembelian Impulsif (Y2) & 0,920 & Reliabel \\
\hline \multicolumn{2}{l}{ Sumber: }
\end{tabular}

Tabel 2. menunjukkan uji reliabilitas pada masing-masing variabel berada pada titik diatas 0,60 yang ditunjukkan pada hasil Cronbach's Alpha, maka dapat dikatakan seluruh instrumen telah memenuhi syarat reliabilitas atau kehandalan sehingga dapat digunakan untuk melakukan penelitian.

Uji normalitas bertujuan untuk mengetahui apakah residual dari model regresi yang dibuat berdistribusi normal atau tidak. Untuk menguji apakah data yang digunakan normal atau tidak dapat dilakukan dengan menggunakan uji Kolmogorov Smirnov. Apabila koesifien Asymp. Sig. (2tailed) lebih besar dari 0,05 maka data tersebut dikatakan berdistribusi normal.

Tabel 3.

Hasil Uji Normalitas Persamaan Regresi 1

\begin{tabular}{|c|c|}
\hline & Unstandardized Residual \\
\hline $\mathrm{N}$ & 75 \\
\hline Kolmogorov Smirnov & 1.161 \\
\hline Asymp. Sig. (2-tailed) & 0.135 \\
\hline
\end{tabular}

Sumber: Data diolah, 2019 
Berdasarkan Tabel 3. maka dapat dilihat bahwa nilai Kolmogorov Smirnov (K-S) sebesar 1,161 sedangkan nilai Asymp. Sig. (2-tailed) sebesar 0,135 . Hasil tersebut mengindikasikan bahwa model persamaaan regresi tersebut berdistribusi normal karena nilai Asymp. Sig. (2-tailed) sebesar 0,135 dimana lebih besar dari nilai alpha yaitu 0,05 .

Tabel 4.

Hasil Uji Normalitas Persamaan Regresi 2

\begin{tabular}{rc}
\hline & Unstandardized Residual \\
\hline $\mathrm{N}$ & 75 \\
Kolmogorov & Smirnov \\
Asymp. Sig. (2-tailed) & 1.341 \\
\hline
\end{tabular}

Sumber: Data diolah, 2019

Berdasarkan Tabel 4. maka dapat dilihat bahwa nilai Kolmogorov Smirnov $(K-S)$ sebesar 1,341 sedangkan nilai Asymp. Sig. (2-tailed) sebesar 0,055. Hasil tersebut mengindikasikan bahwa model persamaaan regresi tersebut berdistribusi normal karena nilai Asymp. Sig. (2-tailed) sebesar 0,055 dimana lebih besar dari nilai alpha yaitu 0,05.

Uji multikolinearitas bertujuan untuk menguji apakah pada model regresi ditemukan adanya korelasi antar variabel bebas. Adanya multikolinieritas dapat dilihat dari nilai tolerance atau variance inflaction factor (VIF). Jika nilai tolerance lebih dari 10 persen atau VIF kurang dari 10, maka dapat dikatakan tidak ada multikolinieritas.

Tabel 5.

Hasil Uji Multikolinieritas Persamaan Regresi 1

\begin{tabular}{ccc}
\hline Variabel & Tolerance & VIF \\
\hline Atmosfer Gerai & 1,000 & 1,000 \\
\hline Sumber: Data diolah, 2019 & &
\end{tabular}

Sumber: Data diolah, 2019

Berdasarkan Tabel 5. dapat dilihat nilai tolerance dan VIF dari variabel atmosfer gerai. Nilai tersebut menunjukkan bahwa nilai tolerance untuk setiap variabel lebih besar dari 10 persen dan nilai VIF lebih kecil dari 10 yang berarti model persamaan regresi 1 bebas dari multikolinieritas.

Tabel 6.

Hasil Uji Multikolinieritas Persamaan Regresi 2

\begin{tabular}{lcc}
\hline \multicolumn{1}{c}{ Variabel } & Tolerance & VIF \\
\hline Atmosfer Gerai & 0,247 & 4,053 \\
Nilai Hedonik & 0,247 & 4,053 \\
\hline
\end{tabular}

Sumber: Data diolah, 2019

Berdasarkan Tabel 6. dapat dilihat nilai tolerance dan VIF dari variabel atmosfer gerai dan nilai hedonik. Nilai tersebut menunjukkan bahwa nilai tolerance untuk setiap variabel lebih besar dari 10 persen dan nilai VIF lebih kecil dari 10 yang berarti model persamaan regresi 2 bebas dari multikolinieritas. 
Uji Heteroskedastisitas bertujuan untuk mengetahui apakah dalam model regresi terjadi ketidaksamaan varians dari residual satu pengamatan ke pengamatan yang lain yang dilakukan dengan uji Glejser. Jika tidak ada satu pun variabel bebas yang berpengaruh signifikan terhadap nilai absolut residual atau nilai signifikansinya di atas atau 0,05 maka tidak mengandung gejala heteroskedastisitas.

Tabel 7.

Hasil Uji Heteroskedastisitas Persamaan Regresi 1

\begin{tabular}{|c|c|c|c|c|c|c|}
\hline \multirow[t]{2}{*}{ Model } & & \multicolumn{2}{|c|}{$\begin{array}{l}\text { Unstandardized } \\
\text { Coefficients }\end{array}$} & \multirow{2}{*}{$\begin{array}{c}\text { Standardized } \\
\text { Coefficients } \\
\text { Beta } \\
\end{array}$} & \multirow[t]{2}{*}{$\mathbf{T}$} & \multirow[t]{2}{*}{ Sig. } \\
\hline & & B & Std. Error & & & \\
\hline \multirow[t]{2}{*}{1} & (Constant) & 0,323 & 0,170 & & 1,904 & 0,061 \\
\hline & Atmosfer Gerai & $-0,021$ & 0,040 & $-0,062$ & $-0,528$ & 0,599 \\
\hline
\end{tabular}

Sumber: Data diolah, 2019

Pada Tabel 7. dapat dilihat bahwa nilai signifikansi dari variabel atmosfer gerai sebesar 0,599 lebih besar dari 0,05 yang berarti tidak terdapat pengaruh antara variabel bebas terhadap absolut residual. Dengan demikian, model yang dibuat tidak mengandung gejala heteroskedastisitas.

\section{Tabel 8.}

Hasil Uji Heteroskedastisitas Persamaan Regresi 2

\begin{tabular}{|c|c|c|c|c|c|c|}
\hline \multirow[t]{2}{*}{ Model } & & \multicolumn{2}{|c|}{$\begin{array}{l}\text { Unstandardized } \\
\text { Coefficients }\end{array}$} & \multirow{2}{*}{$\begin{array}{c}\begin{array}{c}\text { Standardized } \\
\text { Coefficients }\end{array} \\
\text { Beta }\end{array}$} & \multirow[t]{2}{*}{$\mathbf{T}$} & \multirow[t]{2}{*}{ Sig. } \\
\hline & & B & Std. Error & & & \\
\hline \multirow[t]{3}{*}{1} & (Constant) & 0,701 & 0,222 & & 3,153 & 0,002 \\
\hline & Atmosfer Gerai & $-0,003$ & 0,100 & $-0,007$ & $-0,032$ & 0,975 \\
\hline & Nilai Hedonik & $-0,093$ & 0,104 & $-0,207$ & $-0,895$ & 0,374 \\
\hline
\end{tabular}

a. Dependent Variabel : Absres2

Sumber: Data diolah, 2019

Pada Tabel 8. dapat dilihat bahwa nilai signifikansi dari variabel atmosfer gerai yaitu 0,975 dan variabel nilai hedonik yaitu 0,374 . Nilai-nilai tersebut lebih besar dari 0,05 yang berarti tidak terdapat pengaruh antara variabel bebas terhadap absolut residual. Dengan demikian, model yang dibuat tidak mengandung gejala heteroskedastisitas.

Pada penelitian ini digunakan teknik path analysis dalam mengetahui pengaruh atmosfer gerai terhadap nilai hedonik dan pembelian impulsif. Penelitian ini juga menguji peran variabel nilai hedonik dalam memediasi hubungan antara atmosfer gerai terhadap pembelian impulsif.

Perhitungan koefisien path dilakukan dengan analisis regresi melalui software SPSS 21.0 for Windows, diperoleh hasil yang ditunjukan pada Tabel 9. 
Tabel 9.

Hasil Analisis Jalur I

\begin{tabular}{lccccc}
\hline \multirow{2}{*}{ Model } & \multicolumn{2}{c}{ Unstandardized Coefficients } & $\begin{array}{c}\text { Standardized } \\
\text { Coefficients }\end{array}$ & t & Sig. \\
\cline { 2 - 4 } & B & Std. Error & Beta & & \\
\hline (Constant) & 0,675 & 0,238 & & 2,842 & 0,006 \\
Atmosfer Gerai & 0,835 & 0,056 & 0,868 & 14,928 & 0,000 \\
\hline $\mathrm{R}^{2} \quad: 0,753$ & \multicolumn{7}{c}{} & & & \\
\hline Sumber: Data diolah, 2019 & & & &
\end{tabular}

Berdasarkan hasil analisis jalur pada Tabel 9. maka dapat dirumuskan persamaan struktural yang terbentuk adalah sebagai berikut.

$$
\mathrm{Y}_{1}=0,868 \mathrm{X}+\mathrm{e} 1
$$

Persamaan struktural tersebut dapat diartikan yaitu variabel atmosfer gerai memiliki koefisien 0,868 yang artinya atmofer gerai memiliki pengaruh positif terhadap nilai hedonik. Artinya semakin baik atmosfer gerai maka semakin tinggi nilai hedoniknya.

Pada penelitian ini dihitung pengaruh pengaruh atmosfer gerai dan niai hedonik terhadap pembelia impulsif melalui program SPSS 21.0 for windows. Berikut ini ditampilkan hasil perhitungan struktur kedua pada Tabel 10.

Tabel 10.

Hasil Analisis Jalur II

\begin{tabular}{|c|c|c|c|c|c|}
\hline \multirow{2}{*}{ Model } & \multicolumn{2}{|c|}{$\begin{array}{l}\text { Unstandardized } \\
\text { Coefficients }\end{array}$} & \multirow{2}{*}{$\begin{array}{c}\begin{array}{c}\text { Standardized } \\
\text { Coefficients }\end{array} \\
\text { Beta }\end{array}$} & \multirow[t]{2}{*}{$\mathbf{t}$} & \multirow[t]{2}{*}{ Sig. } \\
\hline & B & Std. Error & & & \\
\hline (Constant) & $-0,076$ & 0,320 & & $-0,237$ & 0,813 \\
\hline Atmosfer gerai & 0,439 & 0,144 & 0,395 & 3,053 & 0,003 \\
\hline Nilai hedonik & 0,547 & 0,150 & 0,473 & 3,657 & 0,000 \\
\hline $\begin{array}{ll}\mathrm{R}^{2} & : 0,703\end{array}$ & & & & & \\
\hline
\end{tabular}

Sumber: Data diolah, 2019

Berdasarkan hasil analisis jalur pada Tabel 10. maka dapat dirumuskan persamaan struktural yang terbentuk adalah sebagai berikut.

$$
\mathrm{Y}_{2}=0,395 \mathrm{X}+0,473 \mathrm{Y}_{1}+\mathrm{e}_{2}
$$

Pada pengujian ini akan dilihat nilai masing-masing koefisien determinasi untuk struktur 1 dan struktur 2 serta nilai masing-masing variabel error pada setiap struktur dengan tujuan penyusunan model diagram jalur akhir. Berikut ini hasil perhitungan nilai standar error pada setiap struktur.

$$
\begin{aligned}
& \mathrm{Pe}_{\mathrm{i}}=\sqrt{1-\mathrm{R}_{\mathrm{i}}^{2}} \\
& \mathrm{Pe}_{1}=\sqrt{1-R_{1}^{2}}=\sqrt{1-0,753}=0,515
\end{aligned}
$$




$$
\mathrm{Pe}_{2}=\sqrt{1-R_{2}^{2}}=\sqrt{1-0,703}=0,545
$$

Pada perhitungan pengaruh error (Pe) maka didapatkan hasil untuk pengaruh error struktur $1\left(\mathrm{Pe}_{1}\right)$ sebesar 0,515 dan pengaruh error struktur 2 $\left(\mathrm{Pe}_{2}\right)$ sebesar 0,545. Selanjutnya akan dihitung koefisien determinasi total adalah sebagai berikut:

$$
\begin{aligned}
& \mathrm{R}^{2}=1-\left(\mathrm{e}_{1}\right)^{2}\left(\mathrm{e}_{2}\right)^{2} \ldots \ldots \ldots \ldots \ldots \ldots \ldots \\
&=1-(0,515)^{2}(0,545)^{2} \\
&=1-(0,265)(0,297) \\
&=1-0,053=0,947
\end{aligned}
$$

Pada perhitungan nilai koefisien determinasi total didapatkan 0,947 maka memiliki arti bahwa 94,7 persen variabel pembelian impulsif dipengaruhi oleh atmosfer gerai dan nilai hedonik, sedangkan sisanya sebesar 5,3 persen dipengaruhi oleh faktor lain yang tidak dimasukkan dalam model penelitian atau diluar model penelitian.

Berdasarkan hasil pada Tabel 10. atmosfer gerai memiliki nilai beta 0,868 dan nilai Sig. sebesar 0,000 maka dapat dikatakan $\mathrm{H}_{1}$ diterima karena nilai Sig. 0,000 < 0,05 . Maka dapat diartikan bahwa atmosfer gerai berpengaruh positif dan signifikan terhadap nilai hedonik konsumen di Level 21 Mall Denpasar dengan kata lain semakin baik atmosfer gerai yang diciptakan maka semakin tinggi nilai hedonik konsumen, dan juga sebaliknya

Berdasarkan hasil pada Tabel 11. atmosfer gerai memiliki nilai beta 0,395 dan nilai Sig. sebesar 0,003 maka dapat dikatakan $\mathrm{H}_{2}$ diterima karena nilai Sig. 0,003 < 0,05. Maka dapat diartikan bahwa atmosfer gerai berpengaruh positif dan signifikan terhadap pembelian impulsif konsumen di Level 21 Mall Denpasar dengan kata lain semakin baik atmosfer gerai yang diciptakan maka semakin tinggi pembelian impulsif, dan juga sebaliknya.

Berdasarkan hasil pada Tabel 11 nilai hedonik memiliki nilai beta 0,473 dan nilai Sig. sebesar 0,000 maka dapat dikatakan $\mathrm{H}_{3}$ diterima karena nilai Sig. 0,00 < 0,05. Maka dapat diartikan bahwa nilai hedonik berpengaruh positif dan signifikan terhadap pembelian impulsif konsumen di Level 21 Mall Denpasar dengan kata lain semakin tinggi nilai hedonik yang diciptakan maka semakin tinggi pembelian impulsive, dan juga sebaliknya

Perhitungan pengaruh secara langsung, pengaruh tidak langsung, dan pengaruh total dari masing-masing persamaan struktural yang disajikan dalam Tabel 11. berikut ini.

Pada penelitian yang dilakukan di Level 21 Mall tentang pengaruh atmosfer gerai terhadap nilai hedonik maka didapatkan hasil atmosfer gerai memiliki pengaruh langsung terhadap nilai hedonik dengan nilai sebesar 0,868 atau 86,8 persen. Pada penelitian yang dilakukan di Level 21 Mall tentang pengaruh atmosfer gerai terhadap pembelian impulsif maka didapatkan hasil atmosfer gerai memiliki pengaruh langsung terhadap pembelian impulsif dengan nilai sebesar 0,395 atau 39,5 persen Pada penelitian yang dilakukan di Level 21 Mall tentang pengaruh nilai hedonik terhadap pembelian impulsif maka didapatkan hasil nilai hedonik memiliki 
pengaruh langsung terhadap pembelian impulsif dengan nilai sebesar 0,473 atau 47,3 persen.

Peran nilai hedonik dalam memediasi pengaruh atmosfer gerai terhadap pembelian impuslif. Atmosfer gerai memiliki pengaruh langsung dan pengaruh tidak langsung melalui nilai hedonik terhadap pembelian impuslif dengan nilai koefisien masing-masing sebesar 0,395 dan 0,411, sehingga besaran pengaruh totalnya adalah 0,806 atau 80,6 persen.

Tabel 11.

Pengaruh Langsung, Pengaruh Tidak Langsung dan Pengaruh Total Variabel Atmosfer Gerai (X), Nilai Hedonik (Y $\mathbf{Y}_{1}$ ) terhadap Pembelian Impulsif $\left(\mathbf{Y}_{2}\right)$

\begin{tabular}{lccc}
\hline \multicolumn{1}{c}{ Pengaruh variabel } & $\begin{array}{c}\text { Pengaruh } \\
\text { langsung }\end{array}$ & $\begin{array}{c}\text { Pengaruh tidak } \\
\text { langsung melalui } \mathbf{M}\end{array}$ & Pengaruh Total \\
\hline $\mathrm{X} \rightarrow \mathrm{Y} 1$ & 0,868 & & 0,868 \\
$\mathrm{Y} 1 \rightarrow \mathrm{Y} 2$ & 0,473 & 0,411 & 0,473 \\
$\mathrm{X} \rightarrow \mathrm{Y} 2$ & 0,395 & & 0,806 \\
\hline Sumber: & Data diolah, 2019 & &
\end{tabular}

Keterangan :

$$
\begin{aligned}
& \mathrm{X}=\text { atmosfer gerai } \\
& \mathrm{Y} 1=\text { nilai hedonik } \\
& \mathrm{Y} 2=\text { pembelian impulsif }
\end{aligned}
$$

Uji sobel merupakan alat analisis untuk menguji signifikansi dari hubungan tidak langsung antara variabel independen dengan variabel dependen yang dimediasi oleh variabel mediator. Uji Sobel dirumuskan dengan persamaan berikut dan dapat dihitung dengan menggunakan aplikasi Microsoft Excel 2010. Bila nilai kalkulasi Z lebih besar dari 1,96 (dengan tingkat kepercayaan 95 persen), maka variabel mediator dinilai secara signifikan memediasi hubungan antara variabel terikat dan variabel bebas.

$$
\mathrm{Z}=\frac{\mathrm{ab}}{\sqrt{\mathrm{b}^{2} \mathrm{~S}_{\mathrm{a}}^{2}+\mathrm{a}^{2} \mathrm{~S}_{\mathrm{b}}^{2}+\mathrm{S}_{\mathrm{a}}^{2} \mathrm{~S}_{\mathrm{b}}^{2}}}
$$

Keterangan :

$$
\begin{gathered}
\mathrm{a}=0,835 \\
\mathrm{~S}_{\mathrm{a}}=0,056 \\
\mathrm{~b}=0,547 \\
\mathrm{~S}_{\mathrm{b}}=0,150 \\
\mathrm{Z}=\frac{0,4567}{\sqrt{(0,0009)+(0,0157)+(0,001)}}
\end{gathered}
$$


$Z=\frac{0,4567}{0,0167}$
$Z=3,5348$

Berdasarkan hasil Uji Sobel menunjukkan bahwa hasil tabulasi $\mathrm{Z}=3,5348$ $>1,96$ hal ini menunjukkan bahwa nilai hedonik ( $\left.\mathrm{Y}_{1}\right)$ merupakan variabel yang memediasi atmosfer gerai $(\mathrm{X})$ terhadap pembelian impulsive $\left(\mathrm{Y}_{2}\right)$ atau dengan kata lain atmosfer gerai berpengaruh secara tidak langsung terhadap pembelian impulsif melalui nilai hedonik. Dengan demikian hipotesis keempat diterima.

Berdasarkan hasil pada Tabel 10 atmosfer gerai memiliki nilai beta 0,868 dan nilai Sig. sebesar 0,000 maka dapat dikatakan $\mathrm{H}_{1}$ diterima karena nilai Sig. 0,000 < 0,05. Maka dapat diartikan bahwa atmosfer gerai berpengaruh positif dan signifikan terhadap nilai hedonik konsumen di Level 21 Mall Denpasar dengan kata lain semakin baik atmosfer gerai yang diciptakan maka semakin tinggi nilai hedonik konsumennya, dan sebaliknya.

Ballantine dkk. (2010) menemukan bahwa elemen-elemen atmosfer gerai dapat menjadikan pengalaman berbelanja konsumen menjadi menyenangkan sehingga membangkitkan emosi konsumen dan menciptakan nilai hedonik. Penelitian dari Yistiani dkk. (2012) juga menemukan bahwa atmosfer gerai memiliki pengaruh yang signifikan terhadap nilai hedonik yang berarti semakin baik atmosfer yang diciptakan dalam gerai maka dapat meningkatkan timbulnya nilai hedonik pelanggan pada gerai yang bersangkutan. Menurut penelitian dari Prasetyo dkk. (2016) yang menyatakan bahwa store atmosphere berpengaruh signifikan terhadap hedonic shopping value.

Berdasarkan hasil pada Tabel 11. atmosfer gerai memiliki nilai beta 0,395 dan nilai Sig. sebesar 0,003 maka dapat dikatakan $\mathrm{H}_{2}$ diterima karena nilai Sig. 0,003 < 0,05 . Maka dapat diartikan bahwa atmosfer gerai berpengaruh positif dan signifikan terhadap pembelian impulsif konsumen di Level 21 Mall Denpasar dengan kata lain semakin baik atmosfer gerai yang diciptakan maka semakin tinggi pembelian impulsif konsumennya, dan sebaliknya

Berdasarkan penelitian Roy, (2018) atmosfer gerai seperti tampilan jendela, di signage promosi toko dan tata letak toko memainkan peran penting dalam meningkatkan perilaku pembelian impuls pelanggan. Menurut Vinayagamoorthy \& Kannan (2015) Tahap pra - keputusan pembelian mengasosiasikan pembeli ini dengan pembelian yang tidak direncanakan atau impuls karena toko penuh dengan berbagai produk dan pembeli dapat dengan mudah tertarik untuk membeli produk yang menarik baginya. Menurut Pemayun \& Ekawati (2016), Akram dkk. (2016) Atmosfer gerai berpengaruh positif dan signifikan terhadap pembelian impulsif.

Berdasarkan hasil pada Tabel 11. nilai hedonik memiliki nilai beta 0,473 dan nilai Sig. sebesar 0,000 maka dapat dikatakan $\mathrm{H}_{3}$ diterima karena nilai Sig. 0,00< 0,05 . Maka dapat diartikan bahwa nilai hedonik berpengaruh positif dan signifikan terhadap pembelian impulsif konsumen di Level 21 Mall Denpasar dengan kata lain semakin tinggi nilai hedonik yang diciptakan maka semakin tinggi pembelian impulsif konsumennya, dan sebaliknya

Bedasarkan penelitian ini Prasetyo dkk. (2016) variabel hedonic shopping value berpengaruh signifikan terhadap Impulse Buying, begitu juga dengan 
penelitan Ratnasari dkk. (2015) yang menyatakan bahwa variabel hedonic shopping value berpengaruh signifikan terhadap variabel impulse buying, serta penelitian dari Yistiani dkk. (2012) menemukan bahwa nilai hedonik memiliki pengaruh yang signifikan terhadap pembelian impulsif, yang berarti semakin besar nilai hedonik yang dirasakan pelanggan maka akan dapat meningkatkan kemungkinan terjadinya pembelian impulsif pada gerai yang bersangkutan. Berdasarkan penelitian sebelumnya dapat dibangun hipotesis sebagai berikut.

Berdasarkan hasil Uji Sobel menunjukkan bahwa hasil tabulasi $\mathrm{Z}=3,5348$ $>1,96$ hal ini menunjukkan bahwa nilai hedonik $\left(\mathrm{Y}_{1}\right)$ merupakan variabel yang memediasi atmosfer gerai $(\mathrm{X})$ terhadap pembelian impulsif $\left(\mathrm{Y}_{2}\right)$ atau dengan kata lain atmosfer gerai berpengaruh secara tidak langsung terhadap pembelian impulsif melalui nilai hedonik.

Berdasarkan penelitian dari Yistiani dkk. (2012) menunjukan nilai hedonik sebagai variabel mediasi antara Atmosfer Gerai dan pembelian impulsif tampak tidak memberikan pengaruh yang terlalu signifikan. Kemudian, Setiawati \& Sukawati (2017) menunjukan atmosfer gerai memiliki pengaruh positif dan signifikan secara tidak langsung terhadap pembelian impulsif dengan nilai hedonik sebagai variabel intervening. Serta, penelitian dari Prasetyo dkk. (2016) menunjukan bahwa hedonic shopping value terbukti sebagai variabel intervening dalam hubungan antara store atmosphere dengan impulse buying.

Implikasi dari hasil penelitian ini mencakup dua hal yaitu, implikasi teoritis dan implikasi praktis. Implikasi teoritis berhubungan dengan kontribusinya bagi perkembangan teori - teori mengenai variabel atmosfer gerai, nilai hedonik, dan pembelian impulsif. Implikasi praktis berkaitan dengan kontribusi penelitian kepada pihak perusahaan Level 21 Mall Denpasar sebagai bahan pertimbangan dalam merumuskan kebijakan pemasaran yang berhubungan dengan atmosfer gerai dan nilai hedonik agar dapat merangsang pembelian impulsif.

Hasil penelitian ini dapat memberikan kontribusi empiris tentang hubungan antara variabel atmoser gerai, nilai hedonik, dan pembelian impulsif pada pengembangan ilmu pemasaran. Pengolahan data menggunakan teknik analisis jalur (path analysis) untuk memperkirakan hubungan kausalitas antara variabelvariabel yang telah ditetapkan sebelumnya berdasarkan teori, uji asumsi klasik juga digunakan dalam pengolahan data dalam penelitian ini dengan tujuan untuk memastikan hasil yang diperoleh telah memenuhi asumsi dasar di dalam analisis regresi. Penelitian ini juga menggunakan uji Sobel untuk menguji kekuatan pengaruh tidak langsung variabel atmosfer gerai terhadap pembelian impulsif melalui nilai hedonik. Hasil penelitian ini diharapkan dapat digunakan untuk memperkaya referensi dan ilmu pengetahuan yang berkaitan dengan variabel terkait.

Implikasi dari penelitian ini menekankan pada manfaat nyata dari hasil penelitian untuk mendorong perusahaan - perusahaan yang baru berkembang dan khususnya perusahaan - perusahaan yang telah memiliki penilaian yang positif dimata masyarakat agar mampu memiliki daya saing yang lebih kuat di pasar dan tetap mampu meningkatkan kepercayaan masyarakat terhadap produknya.

Beberapa implikasi strategis dari hasil penelitian adalah Pertama, atmosfer gerai telah terbukti secara positif dan signifikan mempengaruhi nilai hedonik dan 
pembelian impulsif, oleh karena itu atmosfer gerai sebaiknya dapat di tata sedemikian rupa, bersih dan juga rapi, dan juga menempatkan produk - produk terbaru di depan, dan mengganti produk lama, sehingga membuat konsumen merasakan kenyamanan dan pada akhirnya akan tertarik untuk melakukan pembelian di gerai yang bersangkutan Kedua, nilai hedonik konsumen yang positif juga dapat membuat konsumen melakukan pembelian impulsif, pernyataan responden tentang atmosfer gerai yang baik ini menunjukan bahwa atmosfer gerai yang baik akan membuat konsumen memiliki nilai hedonik yang positif, dengan kata lain atmosfer gerai yang baik dapat memberikan rasa nyaman terhadap konsumen sehingga mampu membuat konsumen melakukan pembelian impulsif, inilah salah satu alasan mengapa Level 21 Mall Denpasar harus mampu menjaga dan membuat atmosfer gerai yang baik. Ketiga, keterkaitan antara atmosfer gerai, nilai hedonik, dan pembelian impulsif bisa dijadikan tolak ukur bagi manajemen perusahaan Level 21 Mall Denpasar dalam melihat peluang pasar dengan mempelajari perilaku konsumen untuk tetap dapat membuat konsumen melakukan pembelian secara tidak terencana.

\section{SIMPULAN}

Atmosfer gerai berpengaruh positif dan signifikan terhadap nilai hedonik, hal ini berarti bahwa semakin baik atmosfer gerai maka akan meningkatkan nilai hedonik konsumen di Level 21 Mall Denpasar. Atmosfer gerai berpengaruh positif dan signifikan terhadap pembelian impulsif. Hal ini menunjukkan bahwa semakin baik atmosfer gerai makan akan meningkatkan pembelian impulsif di Level 21 Mall Denpasar. Nilai hedonik berpengaruh secara positif dan signifikan terhadap atmosfer gerai, hal ini menunjukkan bahwa semakin baik nilai hedonik yang dirasakan konsumen maka akan meningkatkan pembelian impulsif di Level 21 Mall Denpasar. Nilai hedonik secara signifikan memediasi pengaruh atmosfer gerai terhadap pembelian impulsif di Level 21 Mall Denpasar. Hal ini berarti bahwa semakin baik atmosfer gerai pada suatu gerai maka akan mampu memperkuat nilai hedonik konsumen terhadap pembelian impulsif. Dalam upaya meningkatkan atmosfer gerai di Level 21 Mall Denpasar diharapkan pihak manajemen Level 21 Mall Denpasar lebih meningkatkan sistem pengaturan udara, karena menurut responden, sistem pengaturan udara di Level 21 Mall masih kurang, hal terasebut dapat dilihat dari masih ada beberapa tempat yang masih terasa panas misalkan seperti lobby awal masuk, lorong di depan toilet. Untuk meningkatkan sistem pengaturan udara di Level 21 Mall, maka kita dapat melakukannya dengan cara menempatkan pendingin ruangan di setiap sudut ruangan agar konsumen merasa sejuk saat berada di dalam gerai.

Dalam upaya meningkatkan nilai hedonik di Level 21 Mall Denpasar sebaiknya pihak Level 21 Mall Denpasar lebih meningkatkan hiburan yang diberikan kepada konsumen, karena menurut responden hiburan yang ada di Level 21 Mall masih kurang, dengan adanya hiburan dapat membuat konsumen merasa senang dan juga lebih terhibur saat berbelanja. Salah satu cara untuk mengadakan hiburan di Level 21 Mall adalah dengan cara mengadakan acara seperti live acoustic agar konsumen merasa terhibur saat berbelanja. Dalam upaya meningkatkan 
pembelian impulsif di Level 21 Mall Denpasar, sebaiknya pihak Level 21 Mall Denpasar lebih memperhatikan penempatan produk baru agar diletakan di tempat yag strategis yang terlihat oleh konsumen, produk lama maximal 1 bulan sekali harus diganti dengan produk baru agar kualitas produknya tetap terjaga, dan penempatan produk best seller di letakan di bagian depan gerai agar terlihat oleh konsumen sehingga konsumen merasa tertarik dan melakuka pembelian tanpa memikirkan akibat.

Dalam upaya meningkatkan pembelian impulsif di Level 21 Mall Denpasar agar konsumen tidak hanya merasakan nilai hedonik, dan merangsang konsumen agar melakukan pembelian impulsif, pihal Level 21 Mall sebaiknya memberikan diskon atau promo pada gerai gerai dan pada saat tertentu, misalnya pada saat liburan, akhir tahun, dan hari raya. Mengganti produk lama dengan produk baru dan menepatkannya di tempat yang strategis juga dapat merangsang konsumen untuk melakukan pembelian impulsive, karena pada saat konsumen melihan produk baru, konsumen cenderung penasaran akan produk tersebut dan juga melakukan pembelian terhadap produk tersebut.

\section{REFERENSI}

Akram, U., Hui, P., Khan, M. K., Hashim, M., \& Rasheed, S. (2016). Impact of Store Atmosphere on Impulse Buying Behaviour: Moderating Effect of Demographic Variables. International Journal of $U$ - and e-Service, Science and Technology, 9(7), 43-60. https://doi.org/10.14257/ijunesst.2016.9.7.05

Angga, A. D., Hudayah, S., \& Wasli, M. (2018). Pengaruh Store Atmosphere Terhadap Impulse Buying. Journal of Applied Business Administration, 2(1), 109-115. https://doi.org/10.30871/jaba.v2i1.746

Ballantine, P. W., Jack, R., \& Parsons, A. G. (2010). Atmospheric cues and their effect on the hedonic retail experience. International Journal of Retail and Distribution Management, 38(8), 641-653. https://doi.org/10.1108/09590551011057453

Bayley, G., \& Nancarrow, C. (1998). Impulse purchasing: A qualitative exploration of the phenomenon. Qualitative Market Research: An International Journal, 1(2), 99-114. https://doi.org/10.1108/13522759810214271

Berčík, J., Horská, E., Gálová, J., \& Margianti, E. S. (2016). Consumer neuroscience in practice: The impact of store atmosphere on consumer behavior. Periodica Polytechnica Social and Management Sciences, 24(2), 96-101. https://doi.org/10.3311/PPso.8715

Choudhary, S. (2014). Study of Impulse Buying Behavior of Consumers. International Journal of Advance Research in Computer Science and Management Studies, 2(9), 1-4.

Dewi, K., \& Giantari, I. (2015). Peran Emosi Positif Dalam Memediasi Store Atmosphere Terhadap Pembelian Impulsif (Studi Pada Konsumen Matahari 
Department Store Duta Plaza Denpasar). E-Jurnal Manajemen Universitas Udayana, 4(12), 4419-4448.

Engel, James F. Roger D Blackwell. dan Paul W Miniard. (1994). Perilaku Konsumen. Alih Bahasa Drs. F.X. Budiyanto. Jilid 1. Jakarta: Binarupa Aksara

Gültekin, B., \& Ozer, L. (2012). The Influence of Hedonic Motives and Browsing On Impulse Buying. Journal of Economics \& Behavioral Studies, 4(3), 180189. https://doi.org/2220- 6140

Harmancioglu, N., Finney, R. Z., \& Joseph, M. (2009). Impulse purchases of new products: An empirical analysis. Journal of Product and Brand Management, 18(1), 27-37. https://doi.org/10.1108/10610420910933344

Hussain, R., \& Ali, M. (2015). Effect of Store Atmosphere on Consumer Purchase Intention. International Journal of Marketing Studies, 7(2). https://doi.org/10.5539/ijms.v7n2p35

Irani, N., \& Hanzaee, K. H. (2011). The effects of Iranian consumers buying tendencies on utilitarian and hedonic shopping value. African Journal of Business Management, 5(17), 7449-7460. https://doi.org/10.5897/ajbm11.257

Kartika, Trecya, Rofiaty, F. (2017). Pengaruh Hedonic Shopping Value Dan Atmosfer Gerai Terhadap Keputusan Pembelian Impulsif Dengan Dimediasi Reaksi Impulsif. Jurnal Bisnis Dan Manajemen, 4(2), 188-197.

Khorrami, M. S., Esfidani, M. R., \& Delavari, S. (2015). The Effect of Situational Factors on Impulse Buying and Compulsive Buying : Clothing The Effect of Situational Factors on Impulse Buying and Compulsive Buying: Clothing. International Journal of Management, Accounting and Economics, 2(8), 2383-2126.

Levy, Michael \& Barton A, Weitz. (2012). Retailing Management. Eighth Edition. New York: McGraw-Hill/Irwin.

Madhuhansi, T. (2017). The Impact of Store Environmental Factors on Customer ' s Impul se Buying Behaviour: Fashion Stores in Colombo District, Sri Lanka. 04(October).

Muruganantham, G., \& Bhakat, R. S. (2013). A Review of Impulse Buying Behavior. International Journal of Marketing Studies, 5(3). https://doi.org/10.5539/ijms.v5n3p149

Pancaningrum, E. (2017). Visual Merchandise Dan Atmosfer Toko: Pengaruhnya Terhadap Keputusan Pembelian Impuls. Jurnal Ilmu Ekonomi Dan Pembangunan, 17(1), 23-40. 
Pemayun, T., \& Ekawati, N. (2016). Pengaruh Promosi, Atmosfer Gerai, Dan Merchandise Terhadap Pembelian Impulsif Pada Hardy'S Mall Gatsu Denpasar. E-Jurnal Manajemen Universitas Udayana, 5(7), 4132-4160.

Prasetyo, W., Yulianto, E., \& Kumadji, S. (2016). Pengaruh Store Atmosphere Terhadap Hedonic Shopping Value Dan Impulse Buying (Survei Pada Konsumen Matahari Department Store Malang Town Square). Jurnal Administrasi Bisnis S1 Universitas Brawijaya, 39(2), 127-134.

Purwa, E. M. R. G., \& Yasa, N. N. K. (2014). Strategi Store Environment Dan Time Pressure Pada Pembelian Impulsif Melalui Emotional State. Jurnal Dinamika Manajemen, 5(2), 147-160. https://doi.org/10.15294/jdm.v5i2.3657

Ratnasari, V. A., Kumadji, S., \& Kusumawati, A. (2015). Pengaruh Store Atmosphere Terhadap Hedonic Shopping Value dan Impulse Buying ( Survei Pada Konsumen Hypermart Malang Town Square ). Jurnal Administrasi Bisniis, 18(1), 1--5.

Roy, A. (2018). The Influence of Store Atmospherics on Consumers ' Impulse Buying : A study on Organized Retail Stores in Kolkata. IMS Management Journal, (0975), 1-13.

Scarpi, D. (2006). Fashion stores between fun and usefulness. Journal of Fashion Marketing and Management: An International Journal, 10(1), 7-24. https://doi.org/10.1108/13612020610651097

Semuel, H. (2006). Dampak Respon Emosi Terhadap Kecenderungan Perilaku Pembelian Impulsif Konsumen Online Dengan Sumberdaya Yang Dikeluakan Dan Orientasi Belanja Sebagai Variabel Mediasi. Jurnal Manajemen Dan Wirausaha, 8(2), 101-115. https://doi.org/10.9744/jmk.8.2.pp.101-115

Setiawati, A. . D., \& Sukawati, T. G. R. (2017). Pengaruh Merchandise dan Atmosfer Gerai Terhadap Nilai Hedonik dan Perilaku Pembelian Impulsif di Lippo Mall Kuta. E-Jurnal Manajemen Unud, 6(9), 5205-5231.

Solomon, Michael, Gary Bamossy, Soren Askegaard and Margaret K. Hogg. (2006). Consumer Behavior:A European Perspective. Third Edition. England : Pearson Education Limited

Sopiah., Syihabudhin. (2008). Manajemen Bisnis Ritel. Edisi 1. Yogyakarta: Andi Offset.

Supriyono, \& Iskandar, D. (2016). Pengaruh Atmosfir Toko Dan Pelayanan Terhadap Nilai Hedonik Dan Pembelian Tidak Terencana Pelanggan Indomaret Surakarta. Aktual, 2(1), 1-19.

Utami, C. W. (2010). Manajemen Ritel: Strategi dan Implementasi Operasional Bisnis Ritel Moderen di Indonesia. Jakarta: Salemba Empat. 
Vinayagamoorthy, D. A., \& Kannan, P. (2015). The impulse buying behavior of consumes for the FMCG products in Jodhpur. Australian Journal of Basic and Applied Sciences, 2(2), 2394-187.

Wahyudi, S. (2017). Pengaruh Price Discount Terhadap Impulse Buying. Valuta, 102(4), 24-25. https://doi.org/10.1002/ejsp.2570

Yistiani, N. N. M., Yasa, N. N. K., \& Suasana, I. G. A. K. G. (2012). Pengaruh Atmosfer Gerai Dan Pelayanan Ritel Terhadap Nilai Hedonik Dan Pembelian Impulsif Pelanggan Matahari Department Storeduta Plaza Di Denpasar. Jurnal Manajemen, Strategi Bisnis Dan Kewirausahaan, 6(2), 139-149.

Yudhistira, R., Fauzi, A., \& Deasyana, L. (2018). Pengaruh Atmosfer Toko Terhadap Nilai Belanja Hedonis Dan Pembelian Tidak Terencana (Survei Pada Konsumen Loka Supermarket Malang City Point). 55(2), 152-159.

Zayusman, F., \& Septrizola, W. (2019). Pengaruh Hedonic Shopping Value dan Shopping Lifestyle Terhadap Impulse Buying pada Pelaggan Tokopedia di Kota Padang. Jurnal Kajian Manajemen Dan Wirausaha, 01, 360-368. 